\title{
ИССЛЕДОВАНИЕ ОСОБЕННОСТЕЙ РЕГУЛЯТИВНЫХ УНИВЕРСАЛЬНЫХ УЧЕБНЫХ ДЕЙСТВИЙ У МЛАДШИХ ШКОЛЬНИКОВ С ЗАДЕРЖКОЙ ПСИХИЧЕСКОГО РАЗВИТИЯ
}

\section{RESEARCH OF PECULIARITIES OF REGULATORY UNIVERSAL EDUCATIONAL ACTIONS IN YOUNGER PUPILS WITH DELAYED MENTAL DEVELOPMENT}

\section{S. Inevatkina \\ O. Terletskaya \\ T. Zuikova}

Summary: The article reveals the concept of "regulatory universal educational actions". The technique of the ascertaining experiment is described. The results of the study of the level of formation of regulatory universal educational actions in primary schoolchildren with mental retardation are considered in detail. The data on the level of formation of attention properties are given; targeting skills; planning and control skills; the ability to assess their capabilities in younger schoolchildren with mental retardation.

Keywords: universal learning actions, regulatory universal learning actions, junior schoolchildren, mental retardation.

\section{Иневаткина Светлана Евгеньевна}

К.nсх.н., доцент, Мордовский государственный педагогический университет им. М.Е. Евсевьева

(2. Саранск),

svetlaj23@mail.ru

Терлецкая Ольга Васильевна

старший преподаватель, Мордовский государственный педагогический университет им. М.Е. Евсевьева

(2. Саранск)

Зуйкова Татьяна Сергеевна

Мордовский государственный педагогический университет им. М.Е. Евсевьева (2. Саранск)

Аннотация: В статье раскрывается понятие «регулятивные универсальные учебные действия». Описывается методика констатирующего эксперимента. Подробно рассматриваются результаты исследования уровня сформированности регулятивных универсальных учебных действий у младших школьников с задержкой психического развития. Приводятся данные об уровне сформированности свойств внимания; умения целепологания; умения планирования и контроля; умения оценки своих возможностей у младших школьников с задержкой психического развития.

Ключевые слова: универсальные учебные действия, регулятивные универсальные учебные действия, младшие школьники, задержка психического развития.

В формате нашей работы была организована и проведена опытно-экспериментальная работа. Базой выступили образовательные организации: МБОУ «Средняя общеобразовательная школа № 22» г.о. Саранск и МБОУ «Средняя общеобразовательная школа № 8» г.о. Саранск. В качестве испытуемых приняли участие младшие школьники с задержкой психического развития.

В данной статье рассмотрим результаты констатирующего эксперимента, цель которого исследование уровня сформированности регулятивных универсальных учебных действий у младших школьников с задержкой психического развития. При проектировании методики констатирующего эксперимента учитывались результаты исследований, в которых транслируется значимость ряда составляющих, а именно устойчивость, переключаемость, распределение внимания; умение понимать и сохранять цель; умение планировать, прогнозировать, контролировать учебные действия в соответствии с задачей, умения оценивать себя и свои возможности при формировании регулятивных универсальных учебных у младших школьников с задержкой психического развития [3; 4]. В итоге в методику констатирующего экспери- 
мента вошли диагностические задания «Корректурная проба», «Расставь знаки», «Графический диктант», «Найди в тексте ошибки».

Данные, полученные на этапе констатирующего эксперимента, были обработаны и подробно проанализированы. В первую очередь, был исследован уровень сформированности внимания и уровень сформированности умения планировать, прогнозировать, контролировать и следовать цели при выполнении задания у младших школьников с задержкой психического развития в экспериментальной и контрольной группах. У большинства испытуемых (72,7 \% в экспериментальной группе и 63,6 \% в контрольной группе) был обнаружен низкий уровень обозначенных регулятивных умений. При выполнении заданий, обучающиеся часто отвлекались, работали на бланке хаотично. Педагог пытался оказать помощь, которая принята не была. Соответственно, задания не были выполнены. Умения планировать, прогнозировать, контролировать и следовать цели, при выполнении задания у младших школьников с задержкой психического развития, не сформированы. Часть испытуемых (27,3 \% в экспериментальной группе и 36,4 \% в контрольной группе) смогли выполнить задания, но допустили незначительные ошибки, продемонстрировав тем самым частично сформированные в соответствии с возрастом умения планировать, прогнозировать, контролировать и следовать цели при выполнении задания.

Далее рассмотрим результаты, полученные при исследовании уровня сформированности умения планировать, прогнозировать, контролировать и следовать цели. У большинства испытуемых (72,7 \% в экспериментальной группе и 63,6 \% в контрольной группе) также уровень сформированности изучаемых умений низкий. Обучающиеся не смогли распределить знаки в соответствии с образцом, путали какие знаки в каких фигурах необходимо указать, с большим трудом пытались контролировать свои действия и следовать цели при выполнении задания, планирование и прогнозирование реализовать не удалось, выполняли задание при непосредственной помощи экспериментатора. Требовалось многократное повторение инструкции, поскольку ее удержание было недлительным. Часть испытуемых (27,3 \% в экспериментальной группе и 36,4 \% в контрольной группе) продемонстрировали средний уровень сформированности изучаемых умений. При выполнении задания у младших школьников с задержкой психического развития возникли трудности в распределении знаков в фигурах, в том числе фиксировались незначительные ошибки, при этом умения планировать, прогнозировать, контролировать и следовать цели при выполнении задания, частично сформированы. Данные испытуемые продемонстрировали все указанные умения.

Следующим шагом был исследован уровень сформи- рованности произвольной регуляции, функции контроля и умения понимать и сохранять цель. У большинства испытуемых с задержкой психического развития был обнаружен низкий уровень: 72,7 \% в экспериментальной группе и 63,6 \% в контрольной группе. Младшие школьники не смогли выполнить задание, даже с подсказками педагога, допустив множество ошибок. Испытуемые не зафиксировали для себя цель задания, часто отвлекались, не прослеживали результат выполнения, подсказки педагога часто оставляли без внимания. Полученное изображение часто их удовлетворяло, даже в ситуации когда оно не было похоже ни на какой предмет. Лишь 27,3 \% испытуемых в экспериментальной группе и 36,4 \% в контрольной группе задание частично выполнили. Прибегая к постоянной помощи экспериментатора, с незначительными ошибками и исправлениями, продемонстрировав средний уровень сформированности исследуемых умений. Младших школьников с задержкой психического развития, которые выполнили задание самостоятельно и правильно, обнаружено не было. Соответственно, не было испытуемых, продемонстрировавших высокий уровень сформированности произвольной регуляции, функции контроля и умения понимать и сохранять цель.

Анализируя результаты, полученные при изучен уровень сформированности умения планировать, прогнозировать и контролировать учебные действия в соответствии с задачей, умения понимать и сохранять цель, функции контроля и произвольной регуляции, были получены данные, которые позволяют утверждать, что у большинства испытуемых (72,7 \% в экспериментальной группе и 63,6 \% в контрольной группе) низкий уровень изучаемых умений. При выполнении задания младшие школьники смогли найти в тексте одну-две ошибки, при этом воспользовавшись помощью педагога. Незначительная часть испытуемых (27,3\% в экспериментальной группе и 36,4 \% в контрольной группе) показали средний уровень исследуемых умений: при выполнении задания с помощью экспериментатора нашли три-четыре ошибки.

Соответственно, результаты, полученные с помощью методик, направленных на исследование особенностей развития регулятивных универсальных учебных действий, позволяют утверждать о том, что у большинства младших школьников с задержкой психического развития низкий уровень сформированности умения планировать, прогнозировать, контролировать учебные действия в соответствии с задачей, умения оценивать себя и свои возможности. Указанные умения являются компонентами регулятивных универсальных учебных действий. Что позволяет сделать вывод о низком уровне сформированности указанных универсальных учебных действий и необходимости планировании дополнительной работы в данном направлении. 


\section{ЛИТЕРАТУРА}

1. Асмолов, А.Г. Как проектировать универсальные учебные действия в начальной школе: от действия к мысли: пособие для учителя / под ред. А.Г. Асмолова. - Москва: Просвещение, 2008. - 151 с.

2. Осмоловская, И.М. Формирование универсальных учебных действий у учащихся начальных классов / И.М. Осмоловская, Л.Н. Петрова. // Начальная школа. - Москва, 2012. - № 10. - С. 6-12.

3. Романова, 0.Н. Формирование у школьников учебных действий самоконтроля и самооценки / О.Н. Романова, Е.В. Пискунова. // Начальная школа плюс до и после. - Москва, 2010. - № 12. - С. 38-42.

( Иневаткина Светлана Евгеньевна (svetlaj23@mail.ru), Терлецкая Ольга Васильевна, Зуйкова Татьяна Сергеевна.

Журнал «Современная наука: актуальные проблемы теории и практики»

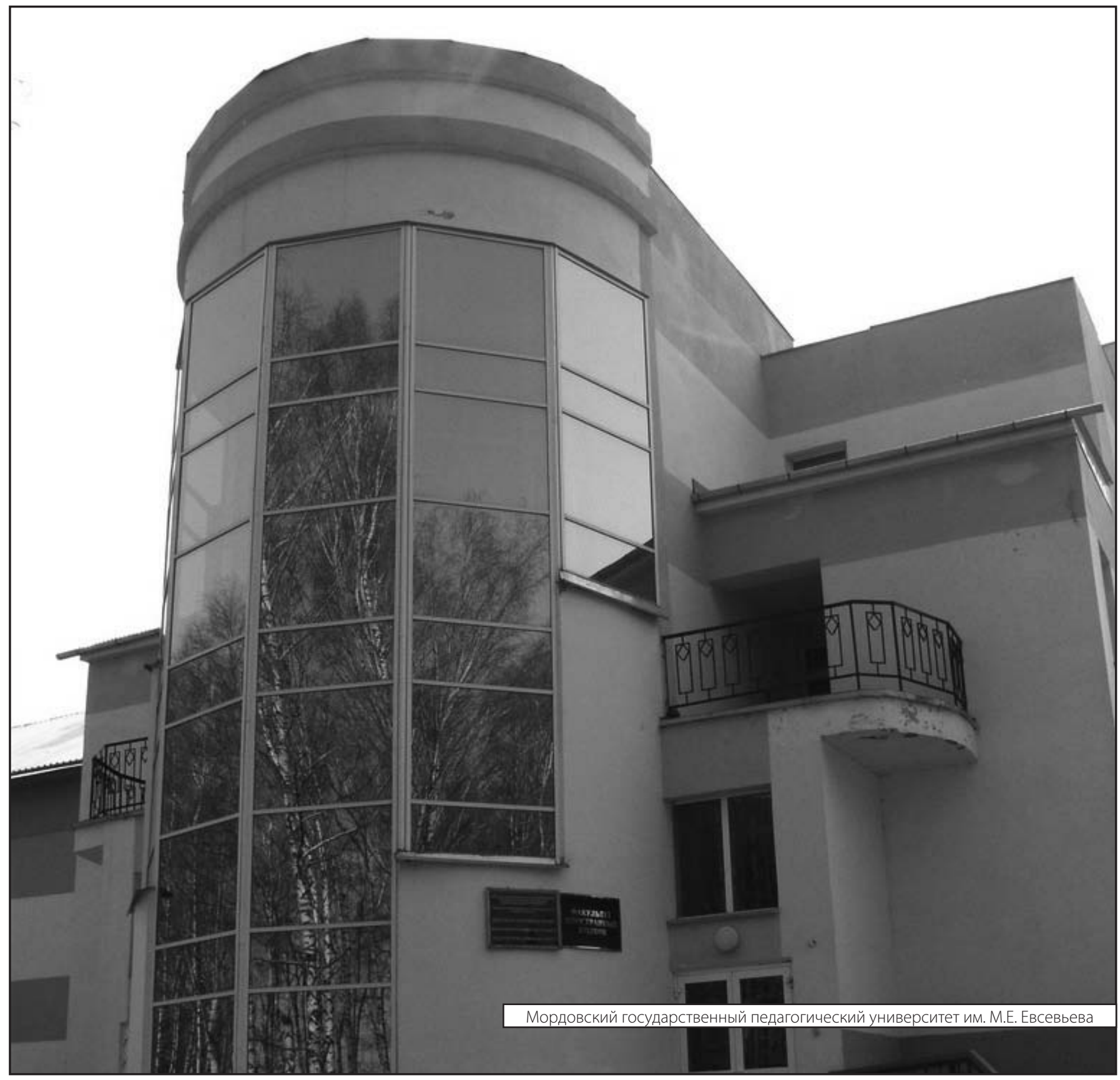

